\title{
Kerklike sake, die kerk en die koninkryk van God
}

\author{
P.J. Strauss
}

Dept. Ekklesiologie

Universiteit van die Oranje-Vrystaat

BLOEMFONTEIN

\begin{abstract}
Ecclesiastical matters, the church and the kingdom of God

Many reformed churches have the following traditional reformed clause in their church orders: 'church assemblies shall iransact ecclesiasical matcers only and in an ecclestasical manmer: Although this principle had, for the first time, been accepted as for hack as the 16th century: vast differences in the imterpretanon sull exist.
\end{abstract}

In this article the author arrwes at the conctusion that wro main lines of interpretation on 'ecclestastical matlers' are to be found among reformed scholars and churches: a church-orientated or categorical point of departure, and the kingdom of (jod as point of departure. He rejects both interpretatums and opts for a thred way, trymg to include and do justice to both the concepts of church and kingdom.

According to the author the church is part of the kingdom, but not the total kingdom. The church has the Hord of God at ils disposal and the Word comments on all facels of crealon 11 does not, however. supply commen on every detal of every facet of craton. 'Licclestastical mallers' therefore include amy matter which 'imtersects', or is imlersected by the message of the Bable

\section{1. 'n Interpretasieproblecm}

Die uitdrukking kerklike sake op kerklike wyse is 'n bekende en wyd aanvaarde gereformeerde norn vir die optrede van die kerk as samelewingskring (Van Dellen \& Monsma, 1967:117; Nauta, 1971:126; Van der Linde, 1983:122). Hierdie uitdrukking se oerfonnulering word gevind by die Provinsiale Sinode van Dordrecht van 1574 in Nederland Hierdie vergadering vereis in sy vyfde artikel dat kerkvergaderings alleen sake wat "k'erkelick" is, moet hanteer (Biesterveld \& Kuyper, 1905:63). Sewe jaar later neem die Nasionale Sinode van Middelburg die sedertdien inin of meer gestandaardiseerde uitdrukking "kerkckelicke 
saecken" op "kerkckelicke wijse" in artikel 21 van sy kerkorde op (Biesterveld \& Kuyper, 1905:147).

Histories en prinsipieel is die oorsprong van die stelreël kerklike sake op kerklike wyse egter nog verder terug te voer. Calvyn self onderskei die "geestelijke regering" (die "geestelijke politie" van artikel 30 van die Nederlandse Geloofsbelydenis [Polman, s.a:7] - PJS) van die kerk van die "burgerlijke" regering van die staatsowerheid (Sizoo, s.a.:235-238) en stuit so op die prinsipiële eie aard verbonde aan die kerk se hantering van sake. In dieselfde denktradisie bly die Nederlandse Sinode van Emden (1571), by al sy simpatie vir die militêre verset van die Nederlandse Prins Willem destyds teen die Roomse Spanje, in gebreke om 'n besluit ter regverdiging van en vir geldelike steun vanuit die kerke aan hierdie verset te neem. F.L. Rutgers (s.a.214) som dit so op:

Het beginsel: geen politieke zaken in de kerk dreef haar schijnbaar, schoon ze het niet uitsprak voorzichtigheidshalve, omdat Prins Willem en velen in den lande het er niet mee eens waren ...

Na die afgooi van die Spaanse juk in 1572 verdwyn die behoefte aan kerklike steun vir hierdie stryd en verander Prins Willem van standpunt op hierdie punt. Daarom spreek Dordt twee jaar later "het beginsel openlijk in de KO uit" (Rutgers, s.a.:214-215): 'n beginsel wat via die Nederlandse gerefonneerde kerkregtelike tradisie 'n aanvaarde norm vir talle gereformeerde kerke word.

Die uitdrukking kerklike sake op kerklıke wyse kom dus vir meer as vier eeue al in gereformeerde kerkordes voor. En log verskil gereformeerdes (of persone verbonde aan tradisionele gereformeerde kerke) soms fel oor die interpretasie en konkretisering van hierdie stelreël: nie soseer oor die 'kerklike wyse' nie, maar oor wat onder 'kerklike sake' verstaan moet word: verskille wat ons kan terugvoer na ' $n$ verskil in die verstaan van die konkrete situasie waarin die kerk homself bevind, maar ook verskille in kerkbegrip - en dan veral oor die verhouding kerk en koninkryk van God. Die volgende voorbeelde illustreer hierdie punt:

- Die interpretasie van 'kerklike sake' in 'n bepaalde situasie dra dikwels "het stempel van haar tijd ... op het voorhoofd" (Hommes, s.a.:5). Hierdie 'stempel' sluit sake in soos die samelewingsomstandighede waarin lidmate verkeer en hulle mening oor waar kerklike optrede in heersende sosiopolitieke nood die nodigste is. Hoe groter die konsensus oor die nood en die sogenaamde Christelike (of koninkryks-) oplossing vir die nood is, hoe groter is die kans dat lidmate dit as geskik vir die kerklike agenda sal beskou.

- Vır sommige is 'n kerklike hupstootjie vir hulle nie-kerklike bedrywighede (Spoelstra, 1989:181) dieselfde as 'in Bybelse wettiging daarvan. Kerklike steun plaas hulle aksie dus in diens van die koninkryk van God. In die $\mathrm{Ne}-$ derlandse situasie ontlok hierdie toedrag van sake van Kuitert (1988:155) 
die snydende opmerking dat diegene wat vandag beweer dat die kerk niks aan die politiek doen nie, daarmee eintlik te kenne gee dat die kerk niks vir die linkse politiek - soos deur hulle voorgestaan - doen nie!

- Ten opsigte van kerkbegrip en die taak van die georganiseerde kerk in die samelewing verskil gereformeerdes soms tot in die wortel van die saak. Op die een uiterste van die spektrum nestel 'n kerksentriese benadering maar ook 'n piëtistiese aanpak wat die kerk in sy optrede wil beperk tot sogenaande intem-kerklike aangeleenthede of die tradisionele 'pie in the sky when you die'. Op die ander uiterste gaan dit om 'n politiek-funksionele ekklesiologie waarin kerklike relevansie gemeet word aan politieke relevansie. Hierin word die waarheidsgehalte en suiwerheid van kerklike uitsprake bepaal deur die waarde daarvan vir 'n bepaalde en oënskynlike sosiopolitiek-bevrydende praxis (Velema, 1972:27; Heyns, 1974:73, Nederduitse Gerefonneerde Kerk, 1986:135).

- Die uitdrukking kerklike sake self stimuleer bes moontlik 'n gekompartementeerde of afgegrensde verstaan van kerklike aangeleenthede, want hierdeur kan die indruk ontstaan dat sommige sake altyd 'kerklik' is, terwyl ander dit nooit kan wees nie. Daarby oordeel byvoorbeeld Vorster (1993) dat so 'n benadering die kerk tot 'n deeltjie van die werklikheid beperk, terwyl die Bybel waarmee hy werk die volle werklikheid - as domein van God die Koning - in sy visier het. Hierdie siening staan 'n koninkryksinterpretasie van hierdie sake dus entistig in die weg (vgl. Vorster, 1993).

Om op te som. Onder gereformeerdes se verstaan van 'kerklike sake' tref ons twee hooflyne van interpretasie aan: die lyn wat die kerk as oriënteringspunt gebruik (deur sommige 'n kerksentriese of kerkistiese benadering genoem), en die lyn wat die koninkryk van God (of Christendom) as die ruimte waar God heers, as oriënteringspunt gebruik. Binne albei benaderings is daar egter ook onderlinge verskille waarin interpretasies soms radikaal van mekaar afwyk én die neiging bestaan dat die mens - in kerk of koninkryk - die maatstaf word.

Teen hierdie probleemagtergrond wil hierdie artikel dus opnuut 'n interpretasie van 'kerklike sake' aan die orde stel. Die vraag wat gestel word, is: moet ons die georganiseerde kerk of die koninkryk van God as oriënteringspunt gebruik? Of, lè die oplossing dalk in 'n derde moontlikheid - 'n moontlikheid waarin albei 'n bepaalde rol speel?

In hulle verstaan van die uitdrukking kerklike sake sluit gerefonneerde kerkregtelikes - altans, diegene op wie se standpunte hierdie stuk konsentreer - ook by die kerklike of koninkrykslyn aan 


\section{Kerksentriese of gekompartementeerde interpretasielyn}

Die gekompartementeerde interpretasielyn van 'kerklike sake' oefen vanaf die sestiende eeu groot invloed in gerefonmeerde kerke uit In hierdie tradisie word ook die benaminge kerklike, gemengde en nie-kerklike sake ontwikkel

Reeds die genoemde Sinode van Dordrecht van 1574 praat van konkrete (en gekompartementeerde, PJS) kerklike sake en sake op die kerklike agenda wat gedeeltelik kerklik en gedeeltelik polities van aard is. Onder laasgenoemde sou dan aspekte verbonde aan die huwelik ressorteer (Biesterveld \& Kuyper, 1905:63). Die Nasionale Sinode van Dordreclit van 1578 neem hierdie onderskeidinge feitlik net so oor (Biesterveld \& Kuyper, 1905:102). Op dieselfde interpretasielyn beweeg die Sinodes van 1916 en 1942 van die huidige Gerefonneerde Kerke in Suid-Afrika. Hier word na huwelikswetgewing, onderwys, die versorging van die armes, onsedelikheid en die eed as voorbeelde van gemengde sake verwys. Maatskaplike, staatkundige en 'streng' wetenskaplike kwessies sou dan moes deurgaan as (permanente, PJS) nie-kerklike sake. Dat hierdie kategorisering egter nie so vas en seker staan nie, word bewys deur die betrokke vergaderings se relativerende byvoeging dat elke kerkvergadering maar vir homself moet uitmaak watter sake onder watter hoof tuishoort (Spoelstra, 1989:181-182). Daar was dus tog by laasgenoemdes die aanvoeling dat 'kerklike sake' hulle nie vir alle tye en onder alle omstandighede in afgegrensde kategorieë laat indruk nie.

Bekende gerefonneerde kerkregtelikes soos F.L. Rutgers (1921:254), H. Bouwman (1985:30-31) en J. Jansen handhaaf eweneens die kerksentriese interpretasielyn. In hierdie proses sluit hulle onkrities aan by die tradisionele onderskejding van kerklike, gemengde en nie-kerklike sake. In sy kommentaar op die Kerkorde van die Gereformeerde Kerke in Nederland gee Jansen byvoorbeeld konkrete voorbeelde van maatskaplike, politieke en wetenskaplike sake wat skynbaar - permanent van kerklike agendas geweer moet word. Daanteenoor noem hy kerklike en gemengde sake waarby die kerk wel kan uitkom (1952:143).

\subsection{Kerksentriese interpretasie neo-Calvinisties?}

Vorster wyt hierdie kerksentriese siening by gereforneerde kerkregtelikes aan die deurwerking van die kerkbegrip van A. Kuyper en dié van die Wysbegeerte van die Wetsidee soos verteenwoordig deur H. Dooyeweerd - 'n rigting wat in die verlengde van Kuyper werk. By sowel Kuyper as Dooyeweerd meen Vorster (1993:216-223) om 'n "beperkende" taakonskrywing vir die kerk waardeur die kerklike "instituut" tot intern-kerklike sake beperk word, te ontdek. Volgens hom stel Dooyeweerd dit uitdruklik dat die kerklike "instituut" nie mag "inmeng" op die terrein van ander "Christelike" samelewingsverbande nie (1993:218) Hierdie "verskralende" benadering, aldus Vorster, hou skadelike gevolge vir die roepingsvervulling van die georganiseerde kerk in (1993:226) 
In die lig van wat alreeds gesê is, verloor Vorster dit dus uit die oog dat die kerksentriese interpretasielyn kerkhistories veel verder teruggaan as selfs Kuyper (1837-1920) (vgl. ook Strauss, 1993:10). Daarby is dit 'n vraag of hy Dooyeweerd korrek weergee. Dit is wel so dat Kuyper se onderskeiding van die kerk as instituut en die kerk as organisme tot 'n kerksentriese benadering lei. Kuyper se onderskeiding impliseer dat die kerk as organisme die samelewing beïnvloed via die kerklidmate in ander lewenskringe (vgl. Kuyper, s.a.:259-260, 272-275; Vorster, 1993:216-217). Wat Dooyeweerd betref, is dit egter te betwyfel of hy die aanduiding van 'n 'soewereiniteit in eie kring' vir die kerk as samelewingsverband kompartementerend of afgrensend bedoel (Vorster, 1993:218). Juis sy komplementering van die soewereiniteit in eie kring van elke samelewingskring met 'n universaliteit in eie kring sowel as 'n vervlegtingsamehang tussen die lewenskringe - iets wat Vorster nalaat - dui op die teendeel (Dooyeweerd, 1968:28, 49). Dit wil dus voorkom asof dit beter is om te sê dat Kuyper se onderskeiding van die kerk as instituut en organisme stukrag aan die bestaande gekompartementeerde interpretasielyn van 'kerklike sake' gegee het (soos by Rutgers en Bouwman) en dat Dooyeweerd en die Wysbegeerte van die Wetsidee - in die verlengde van die neo-Calvinistiese of Kuyperiaanse tradisie - verkeerdelik daarvoor aangewend kon gewees het.

\subsection{Probleme met die kerksentriese interpretasielyn}

Juis in aansluiting by Dooyeweerd (Dooyeweerd, 1963:39 e.v.) moet die neiging tot 'n kompartementering van die onderskeie lewenskringe teenoor mekaar afgewys word Kompartementering stry immers met die Bybelse opvatting van die eenheid en samehang in die ryke verskeidenheid van God se skepping: 'n verskeidenlseid van unieke en me tot mekaar herleibare aspekte, waaronder liefde, omgang en verkeer, reg, gevoel en die fisiese. Hierdie verskeidenheid druk hom ook uit in 'n samelewing wat mettertyd gedifferensieer het, 'n verskeidenheid van unicke ell van mekaar onderskethare (nie skeihare!) lewenskringe.

Trou aan die Bybelse gedagte dat die mens niks nuuts skep nie en slegs binne en vanuit God se skepping en skeppingsorde as raanwerk leef (Ps. 148, Jes. 28, Pred. 1), moet die koninkryk van God as lewensomvattende grootheid bely word (Heyns, 1977:7). In hierdie orde het God nonnatiewe raamwerke of voorwaardes vir elke moontlike menslike vorn van lewe gegee: voorwaardes wat lewenskringe soos kerke, huwelike, gesinne, state, skole en sosiale verenigings eers moontlik makk. Kragtens die verskeidenheid neem 'n bepaalde aspek met sy ken die leiding in die nomatiewe raanwerk van 'n bepaalde lewenskring om sodoende daaraan sy unieke karakter te gee. Kragtens die eenheid en samehang van alles in die skepping funksioneer die keme van die ander aspekte egter ook binne so 'n raamwerk; in diens van hierdie leidinggewende aspek. So kom die normatiewe eie aard van elke samelewingskring na vore. Aan die hand van hierdie orderaamwerke moet die mens sy roeping in die sannelewing vervil. Gevolglik het elke 
samelewingskring sy eie unieke rol om te speel terwyl die samelewingskringe ook wederkerig op mekaar betrekking het en inwerk (Fowler, 1988:28). Ons kan dus differensieer, maar nie kompartementeer of isoleer nie.

Talle voorbeelde in die lewe van die georganiseerde kerk - voorbeelde waarsonder die kerklike lewe nie kan klaarkom nie - illustreer hierdie argument én loënstraf terselfdertyd die moontlikheid van kompartementering.

\subsection{Voorbeelde teen kerksentriese interpretasie}

Oor die leidinggewende funksie van die kerk as samelewingsverband bestaan daar onder gereformeerdes die wyd aanvaarde en verantwoorde opvatting dat dit hier gaan om die Christelike geloof. Imıners, dit is God wat deur sy Skrifwoord en Gees vir Hom 'n gemeente uit die ganse menslike geslag "in die eenheid van die ware geloof vergader" (vraag en antwoord 54 Heidelbergse Kategismus; Ef. 4:3-6, 13). Daarom dat die kerk prinsipieel 'n belydende én belydeniskerk is en geloofsbelydenisse op die tradisionele gereforneerde standpunt die "akkoord van kerklike gemeenskap is" (Kock, 1975:142; Simit, 1984:64). Daarom ook dat die 'mags-' of genademiddele wat God aan die kerk gee (Woord en sakramente) middele tot op- en uitbou van die Christelike geloof is (Velema, 1972:4; Kock, 1975:143-144).

Teen hierdie agtergrond word liefde wat in huwelik en gesin die leiding moet neem, in die kerk as broederliefde in die geloof ( 1 Joh.) gepositiveer; sosiale verkeer word kerklike koinonia in die erediens of "liturgiese viering" (Heyns, 1974 : 42-43) van die geloof; geloofstaal en -simboliek spreek uit die plasing van die kansel, doopvont en Nagmaalstafel in die liturgiese ruimte; en geldelike dankoffers word gegee met die oog op kerkbou en die mak van evangeliese wins. Dat die kerk in 'n gedifferensieerde samelewing nie sonder ander lewenskringe kan klaarkom nie en dat 'sake' in ander kringe soms ook 'kerklike sake' kan word, blyk byvoorbeeld uit die feit dat die staat as regshandlhawer in algemene regsbelang (Dijk, 1945:29-30, Du Plessis, 1941:144-146) aan die kerk ciendomsreg op sy gebou en grond moet waarborg, so nie, sal die ouderlinge in situasies van noodweer self moet wagstaan, dat gemeentes deesdae ook bankrekenings het, dat balansstate op kerklike agendas verskyn (Nauta, 1971:127) en dat swak finansiële diens 'n kerkvergadering kan noop om sy rekening na 'n ander instansie oor te plaas; dat skoolonderwys Bybellees bevorder sodat leesonderrig, as die skool nie daar is nie, soms 'n kerklike saak kan word; dat die nuutste ontwikkelings in die boubedryf ' $n$ kerklike oog vang waar hierdie oog op die verbetering van kerklike fasiliteite ingestel is; dat moderne kommunikasiemiddele en die behoorlike bemeestering daarvan 'n uitsaaidiens op televisie moontlik maak; en dat ouergesag kinders in liefde by die kategese kry, terwyl 'n gebrek daaraan 'n punt op 'n kerkraadsagenda kan word. 
Die vraag is dus nie of sake wat normaalweg in ander lewenskringe gehanteer word 'n 'kerklike saak' kan word nie, maar slegs hoe dit moet gebeur. Daarby volg dit vanuit ons probleemstelling dat die verhouding kerk en koninkryk ook hier verreken moet word. Immers, as dit vir die kerk dan gaan on die Christelike geloof waardeur God as die Koning van alles wat geskape is erken en bely word (Coertzen, 1990:112), moet die kerk in sy eie bestaan en met die middele tot sy beskikking hierdie koninkryk bevorder.

\section{Die koninkryk as interpretasielyn}

Benewens die verskralende en gevolglik skadelike effek van die kerksentriese benadering op die kerk in die vervulling van sy taak in die samelewing, oordeel Vorster (1993:226) dat hierdie benadering die Gereformeerde Kerke in SuidAfrika in die verlede herhaaldelik tot $a d$ hoc en inkonsekwente optredes met betrekking tot praktiese maatskaplike nood gedwing het. Bowendien, aldus Vorster, het ons hier te make met 'n institutêre inperking van die Woord soos bedien deur die kerk (1993:223). Op sy beurt verwerp Spoelstra (1989:182) die neiging dat dit by 'kerklike sake' moet gaan om die standpunt van die kerk. Volgens hom is dit nie die objektiewe aard van die saak wat dit as kerklik kwalifiseer nie, maar "die vraag of en in hoever die Woord van God op die saak lig werp". Sowel Spoelstra as Vorster bepleit gevolglik die koninkryk van God as oriëntasiepunt vir 'kerklike sake'.

\subsection{Heerskappy van Christus en die volle mens}

Vir Spoelstra (1989:182) gaan dit on die vraag na watter aspek van 'n saak om die lig van die Skrif of die heerskappy van Christus vra. Vir hom raak 'kerklike sake' alle gestaltes van Woordverkondiging, 'na binne en na buite'. In die Woord gaan dit om die koningskap van Christus oor die hele mens. Op ' $n$ ander plek stel hy dat daar vanuit "koninkryksperspektief" gevra moet word of die saak die regering van Christus in sy kerk raak. Min of meer in aansluiting by die tradisionele kompartementerende afgrensing van die saak is Spoelstra egter ook van oortuiging dat die evangelie nie 'n sosiale of politieke program bevat nie (Spoelstra, 1989:183). Daarom moet kerklike "voorgangers" nie verwag on altyd die "laaste woord" oor elke politieke, wetenskaplike, kulturele, sosiale, ekonomiese of persoonlike aangeleentheid te spreek nie (Spoelstra, 1989:181).

Die eerste probleem by Spoelstra is dat hy nie in alle opsigte duidelik is nie. Is die "heerskappy van Christus" dieselfde as sy heerskappy "in sy kerk"? En as die kerk dan nie institutêr nie, maar m tenne van die volle mens of die koninkryk van God verstaan moet word: bly daar nog aspekte van die lewe oor wat nie kerklik is nie? Indien wel, val dit nie onder die heerskappy van Christus nie? Die gevalle soos 'n politiek-sosiale program en so meer waarvoor Spoelstra in hierdie 
verband voorsiening maak, dek intussen sekerlik ook 'n bepaalde faset van menswees en hoort Bybels gesien ook onder die heerskappy van Christus!

Aan die een kant vertoon hierdie benadering van Spoelstra 'n dinamiek wat enige moontlike saak op 'n stadium dalk bime die ligkring van die Woord kan bring. Aan die ander kant is daar by hom, in sy afwysing van sekere soorte kerklike uitsprake, 'n neiging tot kategorisering wat dreig om 'n mistigheid oor die konsekwensies van die evangelie te laat toesak.

\subsection{Die begrip kerk so wyd soos die begrip koninkryk}

Vorster hanteer die begrippe kerk en koninkryk sonder enige duidelike onderskeid. Vir hom gaan dit by 'kerklike sake' - as sake wat in die prediking en op kerklike vergaderings aangesny word - prmsipieel om "alles waarom dit gaan in die koms van die Koninkryk". 'Kerklike sake' kall niks anders wees as koninkryksake nie en dit omvat veel meer as net dit wat die 'kerkinstituut' raak. In sy eie woorde gestel:

In ' $n$ tyd van groot maatskaplike veranderinge in Suid-Afrika sal die roeping van die kerke tot sy reg kom as die volle konsekwensies van die koninkryk aanvaar word. Die Gereformeerde Kerke in Suid-Afrika se gesigsveld moet ruim word soos die Koninkryk en uitsprei so ver as die reikwydte van die Woord. (Vorster, 1993:227.)

Wat meer is:

Prediking in die plaaslike kerk en kerklike getuienis in plaaslike kerk- en ekumeniese verband moet die konkrete toepassing van die beginsels van die Koninkryk uitspel vir die gelowiges om dit in sy werksfeer toe te pas. (Vorster, 1993:227.)

In sy (oor)beklemtoning van die koninkryk as oriëntasiepunt vir 'kerklike sake' neig kerk en koninkryk om in hierdie formulerings van Vorster te oorvleuel. Die uitdrukking "konkrete toepassing" van koninkryksbeginsels as kerklike saak onderstreep hierdie waarneming. Die kerk beklee hiervolgens 'n dominerende en omvattende posisie in die koninkryk en samelewing. Konkrete toepassings sal waarskynlik ook nie by Spoelstra met sy nie-kerklike politieke program in goeie aarde val nie. En tog onderskei Vorster ook nie-kerklike terreine in die menslike gemeenskap soos die politiek, ekonomie, kultuur en wetenskap wat gekersten moet word. Soos hy die saak stel, trap hy egter in die slaggat van ' $n$ verkerklikıng van die samelewing in plaas van alles in koninkryksdiens: 'n nuwe kerksentriese in plaas van 'n koninkryksgerigte benadering. Daarby gaan hy uitdruklik verder as die hantering van Bybelse eise vir die koninkryk as 'kerklike saak': dit gaan vir hom ook om die konkrete toepassing van lierdie eise in nie-kerklike situasies wat terselfdertyd 'n (meerdere?) deskundigheid by prediker en kerkvergadering van hierdie situasies veronderstel. Meer nog, hy ontwikkel ook die inte- 
ressante teenstrydige fornulering dat 'kerklike sake' ook meer insluit as dit wat net die 'instituut' raak. Daar is volgens hom dus ook 'kerklike sake' wat deur die georganiseerde kerk gehanteer moet word wat laasgenoemde nie raak nie! Kan dit wees dat daar aan hierdie formulering van Vorster rondon die, vir hom, belasde instituut, reste van die kompartementerende benadering van 'kerklike sake' kleef?

Nie bogenoemde kerksentriese of koninkrykslyne in die interpretasie van 'kerklike sake' bevredig dus nie. Dit kan ook nie, omdat die oplossing nie in 'n óf-ófbenadering lê nie, maar in 'n én-én-benadering: én die koninkryk én die kerk elkeen in die regte mate.

\section{4 'Kerklike sake': én koninkrỵk én kerk}

Dat die kerk in die hantering van al sy sake in diens van die koning van die kerk moet wees, staan Bybels vas. So ook die oortuiging dat die gelowige Christen "oral die lig van die Woord (moet) laat skyn en die koningskap van Christus proklameer" (Vorster, 1993:227; vgl. Nederduitse Gerefonneerde Kerk, 1986:7-8). Daaroor gaan dit nie in lierdie stuk nie.

\subsection{Onderskei kerk en koninkryk}

Waaroor dit wel gaan, is dat die koningskap van Cluristus (God Drieenig) en sy koninkryk meer gestaltes op aarde aanneem as net die Woordgetroue kerk as samelewingsverband: daardie kerk wat vir homself moet uitmaak wat die 'kerklike sake' is wat hy moet hanteer. Daarom is 'n onderskeid tussen die kerk as lewenskring met sy bepaalde rol in die samelewing, en die koninkryk wat die kerk insluit, maar ook breêr loop, vir die beoordeling van 'kerklike sake' van deurslaggewende belang. 'Kerklike sake' kan onmoontlik nie die vestiging van alle fasette van die koninkryk van God wees nie!

Wat wel waar is, is dat die reikwydte van die evangelieboodskap wat die Gees in die hande van die kerk plaas, so wyd soos die koninkryk is. In 'n sekere sin vorn hierdie Woord ook die grondwet van die koninkryk (Vorster, 1993:226: vgl. Nederlandse Geloofsbelydenis, artikel 2). En tog bevat die Bybel nie al die detail van die werklikheid én van die toekomstige bouwerk aan hierdie koninkryk nie: die basiese uitgangspunte daarin verwat, sowel as die Skriftuurlike heenwysings na God se orderaamwerke vir alle skepsels en skepseldinge, is meer rigting- as detailgewend.

Daarby is hierdie Woord nie die alleenbesit van die kerk in erediens, byeenkoms of vergadering nie, maar van elke gelowige politikus, onderwyser en so meer. Hy of sy moet dit dus self ook - desnoods sonder 'n Rooms-georiënteerde kerklike bemiddeling (met die kerk as lewensomvattende genade-instituut - Kleynhans, 
1982:66 e.v.) - vrugbaar aanwend vir koninkryksdiens elke dag op alle lewensterreine. Wie die hantering en deurgee van die Bybelse eise vir die koninkryk die alleenbesit van die georganiseerde kerk maak, is in die greep van 'n natuurgenadedualisme waarvan $\mathrm{K}$. Barth ' $\mathrm{n}$ uitnemende voorbeeld in die reformatoriese kringe van ons eeu is (Strauss, 1993:18 e.v.).

Die primêre belang van die kerk by die Bybel is, interessant genoeg, ook nie in die ekonomiese of esteties-poetiese of antikwariese (ou Bybels en vroeere vertalings) aspekte daarvan geleë nie, maar in die geloofstigtende en lewensrigtinggewende aard van die boodskap daarvan. Vir kerk gaan dit in sy hantering van die Skrif om laasgenoemde as 'n geloofsboek wat primêr gerig is op 'n beslissing van die mens vir Clıristus (Jonker, 1978.12) - met die hele hart en volle lewe Dit bring mee dat 'kerklike sake' alle sake is wat op een of ander manier inspeel op die basiese beginsels van die mens se (geloofs-) verhouding tot God: 'n grondliggende saak wat volledige indienstelling van die mens in die koninkryk medebepaal. Wat meer is, hierdie verstaan van die kerk se hantering van die Skrifboodskap bied die moontlikheid vir die kerk on dit waartoe hy geroep en bevoeg of toegerus is, te doen. Daarby wil dit nie die Skrif kerksentries beperk nie, maar bloot die doel en bestemming van die Skrif samevattend vertolk.

Die georganiseerde kerk is nie dié koninkryk nie, maar deel van die koninkryk En tog is die kerk betrek op die volle omvang van die koninkryk: deur die rigtinggewende reikwydte van die Woord wat hy moet hanteer èn deur die 'natuurlike' samehang van alles met alles, die eenheid in die verskeidenheid van God se wêreld. Deur sy geloofsroeping - soos so pas geskets - in die samelewing te vervul, is die kerk besig met sy bepaalde diens in die volle ruimte van die koninkryk.

Teen hierdie agtergrond kan ons nou poog on 'kerklike sake' te omskryf.

\subsection{Koninkryk én kerk}

Kerklike sake is koninkryksake, maar daar is veel meer sake in die koninkryk as net 'kerklike sake'. 'Kerklike sake' is alle sake waarop die Woord sy lig laat val - die Woord wat in sy kern op die sentrale kontoere van die verhouding God en die mens-skepping gerig is. En, letterlik alle sake kán in hierdie opsig - in die woorde van D. Nauta - op een of ander stadium "een of ander kerkelijk aspect" ontwikkel. Nauta (1971:127) self gee voorbeelde soos kerklike finansies, bouwerk en die lewensbeskoulike kante verbonde aan sosio-politieke kwessies.

So gesien, is tipiese 'kerklike sake' in beginsel alle sake wat op een of ander manier verband hou met die Cliristelike geloof as sentrale kennis- en vertrouensgerigtheid op God en vrug van die werk van die Woord en die Gees van God, alle sake waaraan in regstreekse belang of in diens van hierdie geloof aandag gegee word, of, wat op een of ander manier die belang van hierdie geloof kruis. Anders 
gestel: die kerk as samelewingskring benader alle sake vanuil die hoek van die Christelike geloof as aandurding van die verhouding tussen God en mens in die skepping en gebruik hiervoor primêr die Skrıf.

Hierdie benadering van 'kerklike sake' honoreer die strekking en bestemming ('n uitdrukking van Potgieter, 1983:7,8) van die Skrif, die aard van die georganiseerde kerk (wat struktuur het, al sou ons die benaming instıtuut vermy) en die omvattendheid vall die koninkryk van God (Spoelstra se "heerskappy van Clristus"?) sonder om aan die volgende toe te gee:

- 'n 'Institutêre' beperking op die seggenskrag van die Skrif. Immers, die volgende voorbeelde pas steeds in hierdie benadering: hoewel sport nie noodwendig op die kerklike agenda voorkom nie, kan die voordele van sport vir die totale mens as beelddraer van God of sportverafgoding wel. Dieselfde geld van 'n politieke ideologie wat God se Woord en wet met die verabsolutering van een of ander faset in die skepping probeer vervang. Albei sake ontwikkel 'n kerklike aspek ondat dit op die breë kontoere van die verhouding God en mens in die skepping afstuur. Kerklike uitsprake vanuit die Woord kan hier dus rigtinggewend wees sonder dat sport- of politieke deskundigheid of detail vereis word.

- 'n Beperking van 'kerklıke sake' tot 'n piêtistiese minimoraal (Spoelstra, 1989:181), of aan die ander kant, die meting van kerklike relevansie aan sy ondersteuning van 'n bepaalde praktiese politieke model of beweging. Kerklike uitsprake moet steeds vanuit die Woord en bime die bestemming van die Skrif bly omdat dit die geweldige pretensie inet die Woord as opdrag met hom saandra: So sê die Here ...

- Die neiging dat 'kerklike sake' sonder enige norm benader word en bloot die redelik aanvaarde opvattings van die gemeenskap - oor enige denkbare saak - weerspieël.

On saam te vat. Kerk en koninkryk staan mekaar nie in die weg nie, omdat eersgenoemde deel is van laasgenoende. By die beoordeling van wat 'kerklike sake' is, moet hierdie feit meespeel. So ook die aard van die georganiseerde kerk as samelewingskring wat met 'n sekere bestemming en 'gereedskap' in diens van die koninkryk staan Teen hierdie agtergrond kan enige saak 'n kerklike aspek ontwikkel en vanuit die Woord getuigend, vennanend en rigtinggewend 'gepreek' of 'besluit' of 'gepraat' word.

Die uitdrukking kerklike sake op kerklike wyse skep 'n kompartementerende indruk Hoekom dan mie praat van 'alle sake vanuit kerklike hoek en op kerklike wyse' nie? 


\section{Bibliografie}

BIESTERVELD, P \& KUYPER, H.H 1905. Kerkelijk Handboekje Kampen : J.H Bos BOUWMAN, H. 1985. Gereformeerd Kerkrecht II Kampen: Kok (3e onveranderde druk) COERTZEN, P 1990 Kerkordelike grense vir die kerk (In Du Toit, H \& Kruger, P red. Geroep tot eenheid. Halfway House : NG Kerkboekhandel p. 111-126)

DIJK, K 1945. Kerk en politiek. Franeker : Wever ( $2^{\mathrm{e}} \mathrm{druk}$ )

DU PLESSIS, L.J. 1941. Die moderne staat Stellenbosch : Pro Ecclesia

DOOYEWEERD, H 1963. Vernieuwing en bezinning om het reformatorisch grondmotief. Zutphen : Van den Brink.

DOOYEWEERD, H 1968. The Christian Idea of the State Nutley: The Craig Press

FOWLER, S. 1988. The State in the Light of the Scriptures Potchefstroom : PU vir CHO HEYNS, J.A 1974. Kerk en samelewing (In Duvenage, S.C.W red Reformasie en revolusie. Potchefstroom : PU vir CHO. p. 37-46)

HEYNS, J.A. 1977. Die Kerk. Pretoria : NG Kerkboekhandel

HOMMES, N.J s. a God en keizer in het Nieuwe Testament Franeker : T Wever

JANSEN, J. 1952 Korte verklaring van de Kerkorde der Gereformeerde Kerken Kampen Kok. (3e druk.)

JONKER, W D 1978 Om die regering van Christus in sy kerk Pretoria : Unisa (2e druk)

KLEYNHANS, E P.J 1982 Gereformeerde Kerkreg 1 Pretoria NG Kerkboekhandel

KOCK, P de B 1975. Christelike Wysbegeerte Inleiding Bloemfontein Sacum

KUITERT, H. 1988 Alles is politiek maar politiek is niet alles Baarn Ten Have ( $5^{\mathrm{e}}$ druk)

KUYPER, A s a De Gemeene Gratie II Kampen J H Kok (4e onveranderde druk)

NAUTA, D. 1971. Verklaring van de Kerkorde van de Gereformeerde Kerken in Nederland Kampen Kok

NEDERDUITSE GEREFORMEERDE KERK 1986 Kerk en Samelewing s. I, s. n

POTGIETER, P C 1983 Die gesag van die kerk se Woord Bloemfontein : UOVS.

POLMAN, A D R s. Onze Nederlandsche Geloofsbelijdenis IV Franeker: Wever

RUTGERS, F.L s.a Dictaat I: Kerkrecht s.l, s n

RUTGERS, F.L 1921 Kerkelijke adviezen I Kampen Kok

SIZOO, A. s a Johannes Calvijn Institutie III Delft: W D Meinema (6e druk.)

SMIT, C.J. 1984 God se orde vir sy kerk Pretoria : NG Kerkboekhandel

SPOELSTRA, B 1989 Gereformeerde kerkreg en kerkregering. Hammanskraal : HTS

STRAUSS, PJ 1993 Op die tweesprong? Die Nederduitse Gereformeerde Kerk oor die tema "kerk en samelewing" in Die Kerkorde en Kork e'" Samelewing - 1990 Bloemfontein : UOVS

VAN DELLEN, I \& MONSMA, M 1967 The Revised Church Order Commentary Grand Rapids : Zondervan

VAN DER LINDE, G P L 1983 Die Kerkorde Pretoria : T G van Wyk

VELEMA, W H 1972 Politieke prediking Apeldoornse Studies 5

VORSTER, J.M 1993. Kuyper se ekklesiologie en die interpretasie van 'kerklike sake' in artikel 30 van die Kerkorde van die Gereformeerde Kerke in Suid-Afrika In die Skriflig, 27(2):215-229, Junie 